SOBRE
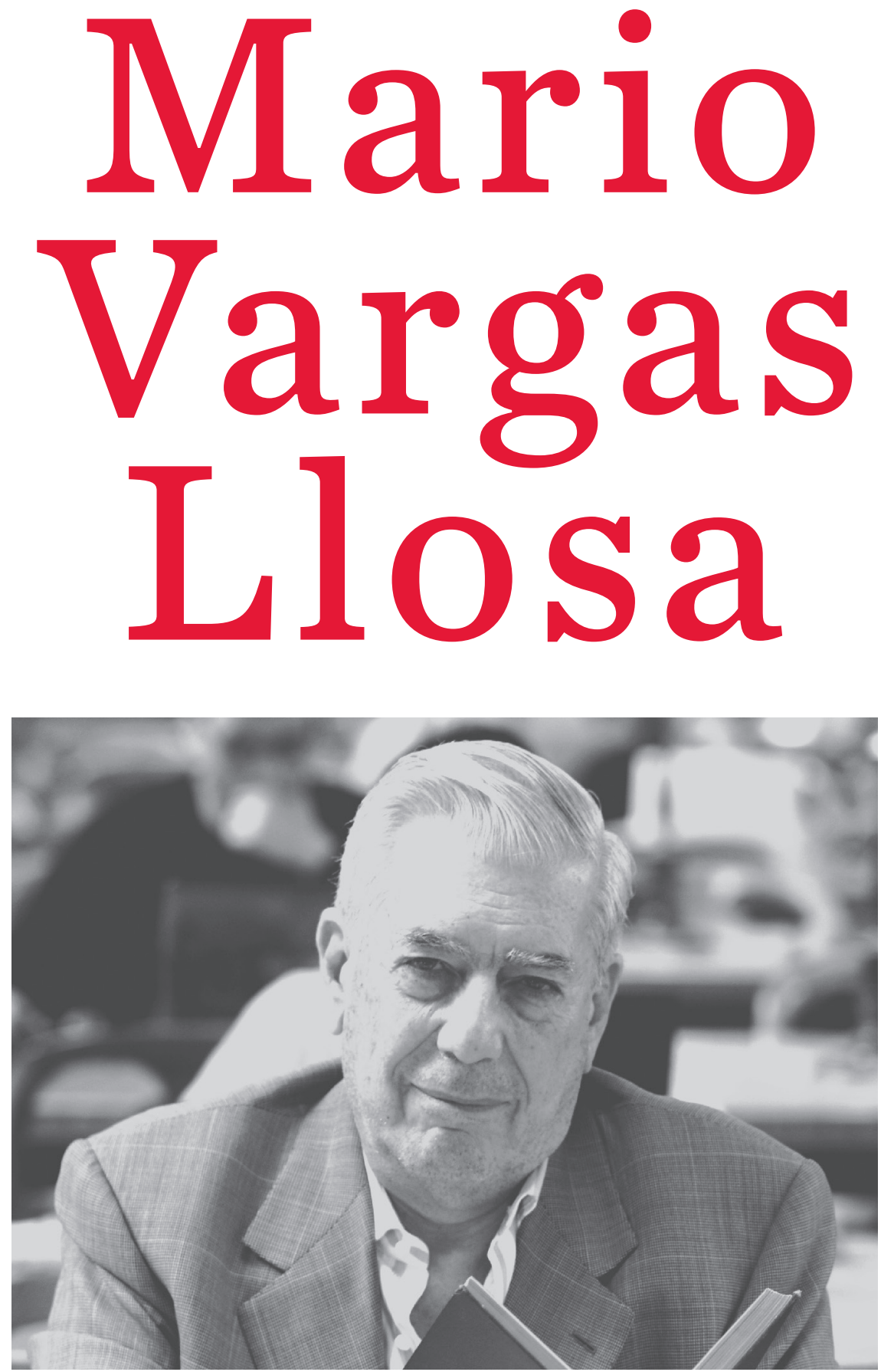

María Jesús Lorenzo-Modia, ed. 


\section{Sobre}

\section{Mario Vargas Llosa}

María Jesús Lorenzo-Modia (ed.)

A Coruña 2019

Universidade da Coruña

Servizo de Publicacións 


\section{Sobre Mario Vargas Llosa}

María Jesús Lorenzo-Modia (editora)

A Coruña, 2019

Universidade da Coruña, Servizo de Publicacións

ISBN: 978-84-9749-729-9 (formato impreso)

ISBN: 978-84-9749-730-5 (formato electrónico, DVD)

ISBN: 978-84-9749-731-2 (formato electrónico, repositorio de la UDC)

Depósito Legal: C 1383-2019

DOI: https:/doi.org/10.17979/spudc.9788497497312

(C) de la edición, Universidade da Coruña

(C) de los textos, los autores

(C) de la imagen de cubierta, Morgana Vargas Llosa

Doble página de guardas: El cielo de Arequipa el 28 de marzo de 1936. Fotografía cedida por Museos científicos, Ayuntamiento de A Coruña

Distribución editorial: <https://www.udc.gal/es/publicacions/distribucion>

Diseño de la cubierta: Julia Núñez Calo

Diseño de interior: Juan de la Fuente

Impresión: Lugami Artes Gráficas, Betanzos (España)

Printed in Spain

Este trabajo ha sido posible gracias al apoyo de la Universidade da Coruña (Vicerrectorado de Economía, Infraestructuras y Sostenibilidad, Campus Innova y Campus Sustentabilidade), MICINN (FEM2015-66937-P, PGC2018-093545-B-100) y de la Xunta de Galicia (Consellería de Cultura e Turismo y Consellería de Educación, Universidade e Formación Profesional, ED431D2017-17). 


\section{ÍNDICE}

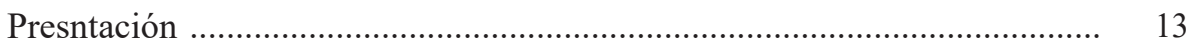

María Jesús LoRenzo-Modia

"Mentiras que tienen apariencia de verdades" o la literatura según Vargas

Llosa

Mario Vargas Llosa

Vela de armas por una luchadora

JuAn CRUZ RUIZ

El padre, la madre y la inspiración

Marie-Madeleine Gladieu

Mario Vargas Llosa, la poesía y los poetas.

\section{EFRAÍN KRISTAL}

La ambigüedad en la narrativa de Mario Vargas Llosa y sus antecedentes en Faulkner, Mann y Borges.

Roy C. Boland OSEgueda

Un escritor del Sur: el anti-colonialismo en algunas novelas de Mario Vargas Llosa desde la perspectiva de J. M. Coetzee.

María ConCePción ReVERTE Bernal

Mario Vargas Llosa: crítica al nacionalismo y al patriotismo

María Jesús LoRenZo-Modia

Entrevista a Mario Vargas Llosa, 22/03/2019 


\title{
Vela de armas por una luchadora
}

\section{Carmen Balcells sacó de las cavernas a la edición española y la incitó a ser ambiciosa y proyectarse por todo el vasto territorio de la lengua ${ }^{1}$}

\author{
MARio VARGas Llosa \\ Premio Nobel de Literatura
}

\begin{abstract}
Cuando la conocí, en los años sesenta, en un vuelo de Londres a Barcelona, Carmen Balcells llevaba un extraño rodete en la cabeza y una camisola que parecía de abadesa. Muchas veces le tomaría luego el pelo recordando ese atuendo. Nunca sospeché en aquel viaje que ella sería en el futuro, además de mi agente literaria, mi amiga más íntima y querida.

Con la franqueza que siempre la caracterizó me dijo en aquella ocasión que había cometido un error aceptando la oferta de Carlos Barral de ser la agente literaria de la editorial Seix Barral, porque la razón de ser de este oficio era defender a los autores frente a los editores y no al revés. La segunda vez que nos vimos, no mucho después, ya había convencido a Carlos que la dejara partir y comenzaba a operar de manera independiente como agente literaria. Consiguió, por lo pronto, que Seix Barral anulara el
\end{abstract}

1 Agradecemos la cesión de los derechos de este artículo por parte de Mario Vargas Llosa. Publicado originalmente en El País el 4/10/2015.

Vargas Llosa, M. (2015). "Vela de armas por una luchadora". Lorenzo-Modia, María Jesús, ed. Sobre Mario Vargas Llosa. A Coruña: Servizo de Publicacións da Universidade da Coruña, 2019, pp. 31-34.

DOI: https://doi.org/10.17979/spudc.9788497497312.031 
leonino contrato que yo había firmado (sin leerlo, claro está) por mi primera novela, La ciudad y los perros, cediendo aquellos derechos por toda la eternidad y concediendo a la editorial una comisión del 50\% sobre todas las traducciones. Había comenzado ya ese largo combate que ella ganaría al cabo de los años en toda la línea y cambiaría para siempre la relación entre escritores y editores en todo el ámbito de nuestra lengua. E, incluso, más allá: recuerdo muy bien el día que me llamó para contarme que, por primera vez en su historia, la editorial Gallimard, de Francia, había aceptado firmar el contrato de un libro por sólo 10 años de duración.

Los editores, al principio, la odiaban y querían acabar con esa intrusa que se enfrentaba con ellos de igual a igual y los obligaba a competir para poder hacerse de un inédito. Algunos ofrecían a los autores pagarles mejores anticipos a condición de que prescindieran de esa intermediaria temible. Llegaron a ponerle un juicio, que, afortunadamente, perdieron. Ella, en las negociaciones, "derramaba vivas lágrimas" (como la princesa Carmesina del Tirant lo Blanc), pero no daba su brazo a torcer y, a menudo, como dicen en España, los ponía a parir. Poco a poco, los editores fueron comprendiendo que lo que Carmen hacía era algo más trascendente que defender los derechos de sus pobres escribidores, es decir, sacar de las cavernas a la edición española, modernizarla, incitándola a ser ambiciosa y proyectarse por todo el vasto territorio de la lengua. Muchas veces, en ese surtidor permanente de ideas que era Carmen, ellos encontraron iniciativas fecundas para lanzar nuevas colecciones, hacer lanzamientos de libros, mejorar sus formatos y conquistar nuevos públicos para la lectura. Sin "la muchacha de Santa Fe", como se autodefinía a veces, el llamado boom de la literatura latinoamericana simplemente no hubiera existido y sus autores habrían pasado desapercibidos del gran público.

Ser representado por Carmen Balcells - algo que llegó a ser el sueño de todos los jóvenes que comenzaban a escribir, en España y América Latina - constituía un verdadero privilegio, pero significaba, también, aceptar su matriarcado y, en todas las decisiones importantes, obedecerle sin chistar. Mil veces discutí con ella y siempre perdí la discusión. Gritaba, lloraba, insultaba, volaban libros y otros objetos por el aire, y siempre terminaba ganando ella, porque, además, casi siempre tenía la razón. Dudo que alguien, en su tiempo, haya conocido mejor, en sus detalles más secretos, la industria editorial y utilizado mejor, siempre en beneficio de autores y lectores, el mercado del libro. 
Nunca conocí una persona tan generosa como Carmen. Con su tiempo, con su afecto, con su inteligencia y, claro está, con su dinero. Algunos de los escribidores a los que - literalmente - mantuvo, porque creía en su talento aunque sus libros tuvieran sólo un puñado de lectores, la traicionaron, y esas decepciones las encajaba con enorme elegancia, pero la hacían sufrir mucho. Se metía en la vida privada de sus autores sin el menor escrúpulo, y siempre para bien. Consolaba a viudos y viudas y, si hacía falta, les buscaba cónyuges de reemplazo; componía matrimonios y parejas, o, si era necesario, los liquidaba. Una vez se pasó toda una noche — sí, toda una noche - tratando de disuadir por teléfono a un editor neoyorquino que la llamó desde Manhattan para decirle que iba a suicidarse (fracasó en su empeño, porque ese mismo amanecer, después de colgar, éste se ahorcó en un poste del alumbrado eléctrico).

La tragedia de su vida fue la gordura. Hizo dietas, frecuentó clínicas —ella me llevó por primera vez a la Clínica Buchinger-, visitó a médicos de medio mundo, y varias veces llegó a bajar de peso. Pero nunca le duraba, porque, tarde o temprano, el apetito, esa tenia insaciable, la vencía, y volvía a engordar. Una noche hizo que se me helara la columna vertebral por la respuesta inesperada que me dio, cuando le conté que, no sé con qué motivo, me llevaron a La Zarzuela y me presentaron al rey Juan Carlos. Su Majestad, lo primero que me preguntó fue: “¿Cómo es esa famosa Carmen Balcells que, según dicen, recorre el mundo vendiendo a los autores españoles?". "Ya ves, Carmen, te has vuelto famosísima". Recuerdo su extraña mirada, la mueca de su cara, y la increíble frase, mascullada en voz muy baja: "¿Quieres que te confiese una cosa? Hubiera dado todo lo que he hecho y alcanzado por ser bonita, aunque fuera un solo día”. “¿Estás hablando en serio o me tomas el pelo?”. Entonces, aparentó que se reía: "Sí, sí, te lo juro, mi sueño fue siempre ser una mujer-objeto".

Hace ya un buen número de años que toda clase de males se abatían sobre su cuerpo. Ella los combatía, con la pugnacidad y constancia con que seguía negociando los contratos. Conservaba la mente lúcida y la misma capacidad de trabajo de siempre; ya no podía caminar y tenía que meterse a clínicas y pasarse horas y días entre médicos. Pero todas las otras horas seguía manteniendo activa y pujante, con horarios enloquecidos que duraban a veces hasta el alba, esa oficina de la Diagonal de Barcelona, a la que tantos escribidores y editores y lectores debemos tanto. 
El último día que la vi, la antevíspera de su muerte, estaba eufórica, llena de proyectos y de bromas. Pero - la visitaba luego de dos y medio o acaso tres meses - nunca la había visto tan acabada físicamente, con tanta dificultad para acomodarse en la sillita de ruedas, con esos súbitos ataques de tos, esa piel lívida, esas ojeras violáceas y el fruncimiento constante de la boca. Tuve entonces la seguridad de que era la última vez que la veía. Murió en su ley, resistiendo, combatiendo, sola en aquel dormitorio repleto de manuscritos que se había propuesto leer hasta el final. Nadie llenará nunca el vacío que deja en el oficio que inventó y llevó a unas alturas desconocidas hasta entonces. Y nadie podrá consolarnos nunca de la tristeza en que nos deja a los que la conocimos y quisimos. 